\title{
La mujer rifeña: un ejercicio de la evolución social bereber
}

\author{
El-Hassan Douhou
}

Resumen

La consideración social de la mujer rifeña, desde finales del

siglo XIX hasta la actualidad, ha sufrido drásticas evoluciones siempre en relación a los lazos nucleares de la tierra y la jerarquización oligárquica basada en la indiscutible autoridad de los hombres. Pese a todo, históricamente se han manifestado diversas vías de escape para la mujer rifeña, valorada especialmente como nutridora de hombres guerreros para la tribu, y, en muchos casos, como ostentadora del honorl deshonor del propio clan.

La irrupción colonial, junto a la presión demográfica y la pobreza de la tierra del Rif, motivaron procesos históricos tales como la emigración de los rifeños a las tierras argelinas y la participación masiva de soldados rifeños en el ejército franquista durante la guerra civil española. Procesos que afectaron profundamente a las bases de la familia $y$, consecuentemente, al papel detentado en ella por la mujer rifeña.

(*) Este artículo es un extracto de la conferencia dada en Nador, en mayo de 1990, en la Asociación Democrática de las Mujeres Marroquíes de Nador. La traducción del original francés ha sido realizada por Rachid A. Raha, siendo revisada por Vicente Moga Romero. 
El origen de mi interés sobre el tema arriba enunciado proviene fundamentalmente de mis investigaciones sobre la propiedad de la tierra en la región del Rif. Parece ser que el rifeño considera la sociedad, en la que cohabita con la mujer, como una pieza principal de su marco tribal, donde podría considerarse a la tierra como la cara de la moneda, y a la mujer, como el reverso.

En realidad, los dos tabúes se conjugan para finalmente expresar la riqueza, el honor, la gloria y la decadencia, aunque la idea original da la primacía a la mujer, marcando con su imagen la conciencia bereber lo que se traduce en las connotaciones matriarcales que refleja el hablar rifeño. Así, los hijos se identifican más con sus madres que con sus padres como indican las palabras rifeñas emmi: mi hijo (de la madre), $y$, uma: mi hermano (o el hijo de mi madre).

Esta pertenencia se traduce simbólicamente por manifestaciones al nivel de la sociedad tribal, lo que no impide, sin embargo, reflejar que la mujer rifeña ha sido la que ha sufrido más en su contexto social. En efecto, si la mujer marroquí, en general, se encuentra en una situación muy crítica, su hermana del Rif no tiene nada que envidiarle, más aún cuando su propia evolución se ha efectuado en el seno de una sociedad en crisis.

La vida de la mujer marroqui en el Rif, durante el periodo colonial, no se realizó en el exterior del hogar. En cuanto a la autoridad, ejercida por los hombres, se debe más al poder de la tribu que a la tutela del derecho musulmán sobre las personas. Por otro lado, seguir la evolución de la mujer rifeña en una sociedad que no ha legado los documentos necesarios no es una tarea fácil. Por ello, la fuente principal que nos queda es, sin duda, la memoria popular, que testimonia sobre el honor, el deshonor, el amor y la democracia de la mujer.

Con frecuencia nos hemos preguntado por qué la mujer rifeña no encarna el heroismo a pesar de las páginas gloriosas de la historia del Rif. Ninguna heroina ha sido celebrada en la memoria histórica del Rif, mientras que sí encontramos heroinas en otras regiones bereberes, como es el caso de Lalla Fadhma N'Soummar, símbolo de la batalla de Ikheridene, desarrollada en la región argelina de Kabilia durante los años 1852 a 1857.

Si la mujer rifeña ha preservado su papel en el interior del hogar, los éxodos explican muchas veces la regresión de sus libertades. En efecto, el espacio permitió a la mujer una expansión en su dominio 
de acción que es el refinamiento directo de su casa, llamado localmente azzarj. La mujer podía en este caso irse libremente a los campos preservando su derecho de promiscuidad y visitando los morabos.

También, es en el Rif central donde encontramos los "zocos de mujeres", como el de arbia de Beni Bu-Ayyach, donde las mujeres pueden hacer sus compras exclusivamente a otras mujeres vendedoras. Pero, lo más extraño en estas comarcas bereberes son las visitas efectuadas para el baño, realizadas durante el día que tiene lugar el zoco semanal, ¡cuando los hombres están ausentes!

Al igual que el hombre, la mujer rifeña, según Miksell ${ }^{1}$, utiliza la seda para sus prendas de vestir. Su vestido es, en general, una túnica larga, con cuello y con un cinturón al nivel del vientre. El uso de la seda fue introducido, en primer momento, en su forma natural, para pasar más tarde a ser confeccionada por las mujeres, sobre todo en las regiones de Jbala, Gomara y Sanhadja. En la llanura el color preferido es el blanco, mientras que la montaña (el Rif profundo) lo son los colores rojo y negro.

También el vestido bereber en el Rif ha sufrido varias influencias, relativamente positivas, sobre todo derivadas de la existencia del gran mercado de Melilla que ha drenado una gran parte de prendas de vestir femeninas de origen inglés.

Por supuesto, es la mujer la que hace posible el nacimiento, la alimentación y el vestido de los hombres de la tribu, pero son los hombres los que hacían las leyes según una lógica racional y la fuerza de las circunstancias. Escogeremos un ejemplo clave como es el caso de la herencia. Aquf encontramos que el reparto de las posesiones hereditarias está dictado por la sharia (la ley islámica), pero existen comarcas donde la propiedad es indivisible. Esto obedece a la necesidad de preservar las sucesivas transmisiones en el seno de las familias donde el esposo ha muerto y que obliga a la mujer a quedarse en la familia del difunto para salvaguardar el patrimonio del peligro de las reparticiones. Ha sido la escasez de terrenos de cultivo la que ha determinado este tipo de reparto del patrimonio, fundamentalmente de la propiedad de la tierra.

Según Mouliéras ${ }^{2}$, algunas de cuyas informaciones he veri-

11.

(1) Marvin Miksell. Northern Morocco: a cultural geography. Berkley,1961, p. 10-

(2) Auguste Moulieras. Le Maroc inconnu, exploration du Rif. Paris; Argel, 1895 
ficado en mis propias investigaciones sobre el terreno en torno a los testimonios de ancianos informantes, la mujer no llegó nunca a alcanzar el grado de servidumbre que algunos autores occidentales le han señalado. Su papel en la célula social era escaso frente a la notoriedad masculina a causa de la jerarquización de las instituciones bereberes. En efecto, la hegemonía de los jefes tribales (amghar) en el seno de la asamblea bereber (ayraw), deja creer en una oligarquía más que en la sumisión de la mujer por el hombre. En cambio, no había iniciativa individual que estimulara una primacía en la esfera social de las mujeres, ya que sus márgenes de maniobra eran muy estrechos. Tomemos, por ejemplo, la repartición del trabajo, que aunque modesta engendraba la confiscación del gran jefe. La preeminencia de la edad tiene igualmente prioridad en el seno de la familia: los grandes o los jefes de familia mandan sobre todas las actividades de los miembros de la tribu. Además, son los jefes de las tribus los que anuncian las campañas agrícolas, dividen las tierras y el agua, y arbitran los conflictos surgidos de estas decisiones.

Es en las fiestas de ostentación (esponsales, bodas...), donde la relación hombre-mujer es directa y la tutela del primero sobre la segunda es clara, pues la mujer debe someterse, a la vez, a la ley de la 128 religión, y al machismo tribal. La mujer debe someterse al marido, a los abuelos, a los hermanos y a los primos hermanos.

Es evidente que la etnia de los irifiyen se asienta en un marco tribal organizado por el hombre y no por la mujer. Así, la asamblea rifeña excluye la participación de las mujeres en los debates políticos, al igual que excluye a los imadyazen (cantantes) y a los imziren (herreros). De todas formas, el origen de la importancia de la mujer con respecto a los hombres guerreros está, ante todo, vinculado al clan: queda constancia del hecho de que las mujeres nutren a la tribu de guerreros capaces de empunar las armas y defender la tierra y el honor.

A finales del siglo XIX, todos los autores estaban de acuerdo en afirmar la independencia de las tribus rifeñas. La fuerza de las fricciones de las dos confederaciones (ikaríyen e ishabdanen) descansaban sobre el número de fusiles que tenía cada parte. Las desigualdades de población y de armas posibilitaron el desencadenamiento de los conflictos en los límites territoriales, lo que marcó el inicio de los enfrentamientos intestinos (intertribales), tema que hemos tocado en mayor profundidad en nuestra tesis sobre la propiedad territorial, presentada en la Universidad de Brest, y actualmente en prensa. 
La tierra habfa ocultado otro aspecto de esta sociedad, tan importante como la fuerza invertida en la lucha contra los extranjeros en defensa del honor. Este formaba parte crucial de todo conflicto, como han puesto de manifiesto los estudios de David M. Hart sobre la tribu de los Ait Wariaghel, y de Raymond Jamous sobre la fracción de los Ait Sidel, en el Rif Oriental.

Según Auguste Moulieras ${ }^{3}$ el conflicto que oponía a los Beni Said y a los Beni Bu Yahi, estaba causado por la humillación sufrida por las mujeres de la segunda tribu en su visita al morabo de Sidi Aissa, que se encuentra en el territorio de la primera. Los conflictos de honor se activaron en las cuestiones que hacían alusion a las mujeres sin escrúpulos, pero sobre todo venían ligados a la perversidad de los hombres. Así, en caso de adulterio, la familia castigaba al culpable y a la víctima, llegando incluso hasta el destierro. Los principios eran muy claros para los ikariyen: la vecindad y la proximidad de las casas hacían que la mujer fuese la primera víctima a señalar.

Al nivel social, el hombre (marido, padre y hermanos) es considerado como tutor de la mujer. En caso de ausencia de los tutores, doce personas próximas podían tomar a la mujer a su cargo en caso de matrimonio. Esto, según la sharia islámica, forma la denominada lafif

La evolución demográfica y la pobreza del espacio de producción creó desequilibrios entre los recursos y la poblacion, lo que empujó a una parte de los hombres a emigrar a Argelia desde 1930. La ausencia de los hombres del duar durante todo el año provocaba una crisis en el nivel social, aunque no tenía aspectos visibles salvo en el nivel de las tareas agrícolas, donde eran los niños, los ancianos y las mujeres, los que se ocupaban del espacio ingrato del duar.

A finales de los años treinta la escasez de lluvias fue notoria en las regiones de Kelaya y de Melilla, acentuando las necesidades migratorias. Más tarde, en 1936, la guerra civil española se constituirá en el fenómeno migratorio de mayor envergadura. En efecto, antes del $18 \mathrm{de}$ julio de 1936, fecha del alzamiento de las tropas franquistas, habia unos nueve mil hombres en las tropas regulares de las fuerzas coloniales españolas y otros ocho mil en fuerzas auxiliares. Estos miles de rifeños

(3) Ibid.

(4) Véase el documento jurídico del derecho de la mujer respecto al hombre: Muduanat al ahwal al chakhsiat. 
verían incrementado extraordinariamente su número a más de veinticinco mil hombres, que formarían una parte crucial del ejército de Franco durante la guerra civil (1936-1939). El número de estas reclutas alcanzó en la primavera de 1937 , la cifra de treinta y cinco mil ochenta y nueve hombres. El número global de los rifeños que participaron en la guerra civil española, ascenderfa a unos setenta mil hombres según algunos autores.

Muchos soldados rifeños murieron en esta lejana guerra. Atraídos sobre todo por la promesa de mejores salarios, los marroquíes acudieron en gran número a enrolarse en el ejército franquista. Las malas cosechas de los años precedentes hicieron fácil el reclutamiento de estos hombres a los caides. Pero, será sobre todo, en el Rif Oriental, y concretamente en la región de Kelaya, que rodea a Melilla, donde los reclutamientos eran ya tradicionales, donde estos serán, en esta ocasión, masivos ${ }^{6}$.

Una extensa literatura celebra los aspectos psíquicos de la emigración, la poesía forma parte primordial de este acervo literario y está inspirada en los sufrimientos. Una poetisa desconocida de la tribu de Tensaman-kiuch, dirigió a su marido emigrante en Argelia el poema siguiente?:

Vuelve joh Moh mio!

abandona ese trabajo penoso

todo el mundo ha vuelto de alli con los bolsillos llenos

y tú, ni un duro

tu hogar está a merced de los vagabundos

y tu tierra repartida entre los herederos

La ausencia de los hombres, de sus hogares, durante algún tiempo, quebranto las familias sobre todo, por lo que se conoce, en la región de Tensaman, ya que sus hombres permanecían, como obreros estacionales, de tres o cuatro años, fuera de sus familias. Además, pocos

(5) María Rosa de Madariaga. "L'image et le retour du maure dans le memoire collective du peuple espagnol et la guerre civile de 1936". In: Revue internationale de recherche et de synthèse en sciences sociales, Paris, 1988, $n^{2} 90$, p. 74.

(6) S. Biarnay. Etudes sur les dialectes berbères du Rif. Paris, 1917

(7) María Rosa de Madariaga. Art. cit., p. 75. 
rifeños pudieron establecerse definitivamente en ciudades argelinas como Orán y Dahra ${ }^{8}$.

(8) Luis Milliot. "L'exode saisonnier des rifains vers l'Algérie". In: Bulletin Economique des Maroc, Rabat, 1934, I, n² 5-6, p. 141. 